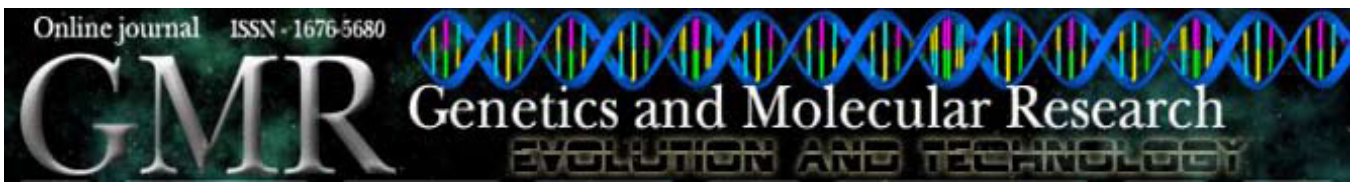

\title{
Meiosis, spermatogenesis and nucleolar behavior in the seminiferous tubules of Alydidae, Coreidae and Rhopalidae (Heteroptera) species
}

H.V. Souza, F.B. Souza, S.R.C. Maruyama, M.M.U. Castanhole and M.M. Itoyama

Departamento de Biologia, Laboratório de Citogenética e Molecular de Insetos, Instituto de Biociências, Letras e Ciências Exatas, Universidade Estadual Paulista Júlio de Mesquita Filho, São José do Rio Preto, SP, Brasil

Corresponding author: M.M. Itoyama

E-mail: mary@ibilce.unesp.br

Genet. Mol. Res. 8 (4): 1383-1396 (2009)

Received August 12, 2009

Accepted September 21, 2009

Published November 17, 2009

ABSTRACT. We studied the karyotype, spermatogenesis and nucle-
olar activity at spermatogenesis in five species of Heteropera: Hy-
alymenus sp and Neomegalotomus pallescens, Alydidae; Catorhin-
tha guttula and Hypselonotus fulvus, Coreidae; and Niesthrea sidae,
Rhopalidae. They showed a red (Alydidae) or orange (Coreidae and
Rhopalidae) membrane covering the testes, which consisted of seven
testicular lobes, except in N. pallescens, which had only five. All the
species had m-chromosomes, an X0 sex chromosome system and 10
(Hyalymenus sp, N. pallescens, and N. sidae), 16 (H. fulvus) or 22 (C. 
guttula) autosomes. Similar to the other species described to date, all these species showed holocentric chromosomes, interstitial chiasmata in most autosomes, and autosomes dividing reductionally in the first meiotic division and equationally in the second, while sex chromosomes, divided equationally and reductionally in the first and second meiotic divisions, respectively. In addition, we observed that the sex chromosome is heteropycnotic at prophase and that heteropycnotic chromosomal material is found in the nuclei at spermatogenesis; variation in size, shape and location of the nucleolar material occurs during spermatogenesis, denoting a variable degree of activity in the different stages.

Key words: Hemiptera; Testicular lobes; Spermatogenesis; Spermiogenesis; Nucleolus

\section{INTRODUCTION}

The Heteroptera are the largest and most diverse group of insects with incomplete metamorphosis. They are generally treated as a suborder of Hemiptera. This group includes approximately 75 families; most of them can be found in almost all the continents (except the Antarctic) and some islands. Its long evolutionary history and the apparent adaptability of the Heteroptera have resulted in great biological and structural diversity (Schuh and Slater, 1995).

The Heteroptera are characterized by holocentric chromosomes, in which the kinetochore structure is absent in meiotic cells (Motzko and Ruthmann, 1984; Rufas and Giménez-Martín, 1986; Wolf, 1996) and kinetic activity is restricted to the chromosome tips (Motzko and Ruthmann, 1984; González-Garcia et al., 1996). According to Schaefer and Panizzi (2000, apud Ventura and Panizzi, 2003), species of the family Alydidae usually have a chromosome number of $2 n=10 A+2 m+X 0$ or $7 A+2 m+X 0$. Sands (1982) found an X0 sex chromosome system in six species of the Alydidae. In three of these species (Riptortus linearis $\mathrm{F}$., R. pedestris and Riptortus $\mathrm{sp}$ ), the chromosome number was $2 \mathrm{n}$ $=13$, X0, while in the other three (Leptocorisa acuta T., L. chinensis D. and L. oratoria), it was $2 \mathrm{n}=17, \mathrm{X} 0$.

The most common sex chromosome system in the Coreidae is $\mathrm{X} 0 / \mathrm{XX}$ (male/female), though $X_{1} X_{2} / X_{1} X_{1} X_{2} X_{2}$ (male/female) is found as well (Parshad, 1957). Another characteristic of this family is $\mathrm{m}$-chromosomes. The diploid chromosome number in the males of other species of this family range from $13(10 \mathrm{~A}+2 \mathrm{~m}+\mathrm{X} 0)$ to $28(24 \mathrm{~A}+2 \mathrm{~m}$ + X1X2) (Ueshima, 1979; Sands, 1982; Manna, 1984; Colombo and Bidau, 1985; Dey and Wangdi, 1988; Satapathy and Patnaik, 1989; Cattani and Papeschi, 2004; Souza et al., 2007a). Bressa et al. (2001) examined 24 Rhopalidae species and found a pair of mchromosomes, an X0 sex chromosome system and a chromosome complement of $2 \mathrm{n}=13$ $(10 \mathrm{~A}+2 \mathrm{~m}+\mathrm{X} 0)$ in all of them.

In most arthropod species, the nucleolus disorganizes in the diplotene stage or diakinesis. Because of this, small silver-impregnated bodies usually cannot be visualized 
in metaphase until telophase II. When spermatids are being formed, the nucleolus initiates its reorganization, indicating recommencement of rRNA transcription. The nucleolus then finally reorganizes at the end of spermatid development (Bressa et al., 2003). However, some exceptions have been reported. In Asellus aquaticus (Isopoda), silver nitrate-nucleolus organizer region (NOR) bodies were visualized in every spermatogenesis (Di Castro et al., 1983). In Callicrania seoanei (Orthoptera), not only were NORs observed during both divisions, but also nucleolar bodies were found dispersed among the chromosomes during interkinesis and in pro-metaphase II (Santos et al., 1987). In Triatoma infestans and T. sordida (Heteroptera, Reduviidae), Ag-NOR bodies were observed until metaphase I (Tavares and Azeredo-Oliveira, 1997). In Carlisis wahlbergi (Heteroptera, Coreidae), nucleolar semi-persistence (presence of nucleolar bodies in metaphase) has been reported until metaphase II (Fossey and Liebenberg, 1995), while in Acanthocoris sordidus (Heteroptera, Coreidae) and Coptosoma punctissimum (Heteroptera, Plataspidae), nucleoli were observed at the metaphase plate in both primary and secondary spermatocytes (Bressa et al., 2003). Among other Heteroptera, exceptions to this behavior have been described, such as in Nysius californicus (Lygaeidae; Souza et al., 2007b) and Antiteuchus tripterus (Pentatomidae; Souza et al., 2007c). In both cases, material impregnated with silver was observed around the periphery of the chromosome in metaphase I.

Especially due to the diverse diploid chromosome numbers, different sex chromosome systems, and variations in the morphology and positioning of the nucleolar material during spermatogenesis, we examined the cytogenetic and nucleolar characteristics, as well as modifications that occur during spermatogenesis in Hyalymenus sp and Neomegalotomus pallescens (Alydidae), Catorhintha guttula and Hypselonotus fulvus (Coreidae), and Niesthrea sidae (Rhopalidae).

\section{MATERIAL AND METHODS}

The insects were collected in São José do Rio Preto (2047’32” S, 49²1'37” W), SP, Brazil, from Paspalum sp (Poaceae) (Alydidae), Lycopersicon sculentum L. (Solanaceae) (Coreidae) and Parthenium hysterophorus L. (Asteraceae) (Rhopalidae). An average of 10 individuals per species (Hyalymenus sp and N. pallescens, Alydidae; C. guttula and H. ful$v u s$, Coreidae; N. sidae, Rhopalidae) were analyzed. Seminiferous tubules were obtained by dissecting adult males, and slides were prepared with the squash technique and stained with lacto-acetic orcein dye and silver nitrate, using a specific technique (Howell and Black, 1980) for staining the NORs. All images were obtained with a Zeiss microscope and were processed with the AXIO VISION software.

\section{RESULTS}

\section{Chromosome observations in meiotic cells stained with lacto-acetic orcein}

The cytogenetic characteristics of spermatogenesis in Hyalymenus sp and $N$. pallescens (Alydidae), C. guttula and H. fulvus (Coreidae) and N. sidae (Rhopalidae) after staining with lacto-acetic orcein are summarized in the Table 1. 
H.V. Souza et al.

1386

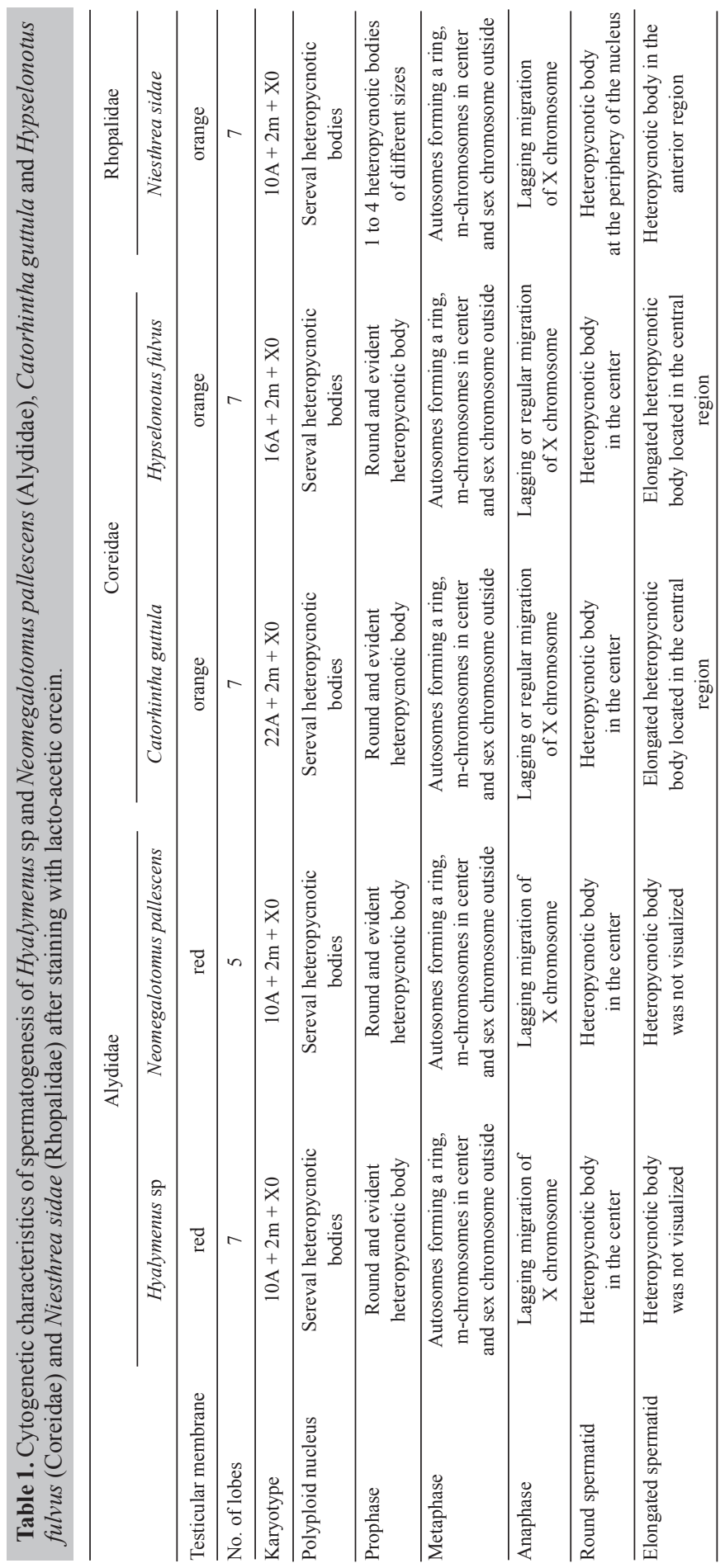

Genetics and Molecular Research 8 (4): 1383-1396 (2009)

CFUNPEC-RP www.funpecrp.com.br 


\section{Alydidae}

In both species of Alydidae, Hyalymenus sp and N. pallescens, the testes are covered by a red membrane, which encloses seven testicular lobes in Hyalymenus sp and five in $N$. pallescens. The polyploid nucleus possesses several heteropycnotic bodies (Figure 1a). As in other species of Heteroptera, spermatogenesis is cystic and the cells are contained in an envelope formed by a single layer of cells (Figure 1b).

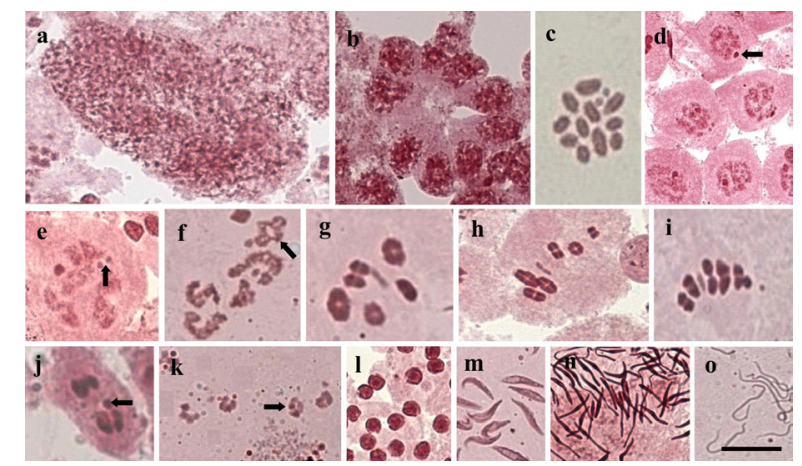

Figure 1. Cells of the seminiferous tubules of adult males of Hyalymenus sp (a, b, d, e, h, l, n) and Neomegalotomus pallescens (c, f, g, i, j, k, m, o) (Alydidae) stained with lacto-acetic orcein. a. Polyploid nucleus. b. Spermatogonial cyst. c. Spermatogonial metaphase. d. Prophase I (leptotene), arrow: heteropycnotic sex chromosome. e. Prophase I (zygote), arrow: m-chromosomes. f. Prophase I (diplotene), arrow: autosome with an interstitial chiasma. g. Diplotene/diakinesis, with $\mathrm{m}$-chromosomes at the center of the ring. h. Metaphase I. i. Metaphase II. j. Anaphase II with the lagging migration of the sex chromosome (arrow). k. Telophase II, arrow shows the heteropycnotic material. I. Round spermatids. m-o. Spermatids in elongation. Bar: $10 \mu \mathrm{m}$.

As is generally reported for Heteroptera, we found holocentric chromosomes, the sex chromosomes segregated equally in the first division and reductionally in the second, with the inverse occurring in the autosomes; there was lagging migration of the sex chromosome. Autosomes showed one or two chiasmata, which were terminal or interstitial. They also showed achiasmatic m-chromosomes.

The mitotic metaphase in the males of these two species showed 11 larger chromosomes (which included 10 autosomes plus the sex chromosome) and two m-chromosomes (Figure 1c). The karyotype of Hyalymenus sp and N. pallescens males was $2 \mathrm{n}=10 \mathrm{~A}+2 \mathrm{~m}+\mathrm{X} 0$. The sex chromosome system in both species was X0. Meiotic behavior of these two species was very similar. The sex chromosome and the m-chromosomes both condense earlier than autosomes, which could be seen from initial prophase through the subsequent phases. In both species, the meiotic cells in prophase I (from leptotene until diplotene) stained with lacto-acetic orcein exhibited a heteropycnotic body that was probably the X chromosome, which is observed in the nuclear periphery (Figure 1d-f). During diplotene/diakinesis, an interstitial chiasma was observed in one or two autosomes (Figure 1f,g). In polar view, the autosomes in metaphase I were arranged in a circular manner, with the m-chromosomes lying in the circle and the sex chromosome generally located outside (Figure 1g). In a lateral view, the chromosomes were arranged side by side (Figure 1h). Metaphase II can be observed in Figure 1i. The migration of the sex chromosomes in anaphase II was lagging, as shown in Figure 1j. In telophase, heteropycnotic material can be observed (Figure 1k). At the beginning of spermiogenesis, heteropycnotic material was seen inside the round spermatid nucleus (Figure 11). Later, when the nucleus was beginning to elongate to form the spermatozoon, the heteropycnotic material was not seen (Figure 1m-o). 


\section{Coreidae}

The testes of C. guttula and H. fulvus are formed by seven testicular lobes and are covered by an orange membrane, only differing in coloration intensity. In H. fulvus, staining of the basal region was more intense than in the apical region. Since spermatogenesis in these two species had similar characteristics, the results are shown together. The polyploid nucleus was large and possessed several small heteropycnotic regions (Figure 2a). At the beginning of spermatogenesis (leptotene-pachytene) (Figure 2b-e), the chromosome condensation process was observed, as well as a round and very evident heteropycnotic body that persisted almost until the end of prophase (Figure 2f). These species possess evident interstitial chiasmata, which could be visualized in the chromosomes with cross morphology (Figure 2f). The chromosome complement of $H$. fulvus was $2 \mathrm{n}=16 \mathrm{~A}+2 \mathrm{~m}+\mathrm{X} 0$ (Figure $2 \mathrm{~g}$ ) and $C$. guttula showed $2 \mathrm{n}=22 \mathrm{~A}+2 \mathrm{~m}+\mathrm{X} 0$ (Figure $2 \mathrm{~h}$ ). In polar view, the autosomes formed a ring, with the m-chromosomes in the center and the sex chromosome outside the ring formed by the autosomes (Figure 2g). During anaphase and telophase, lagging migration of the chromosomes was sometimes evident (Figure 2i-k).

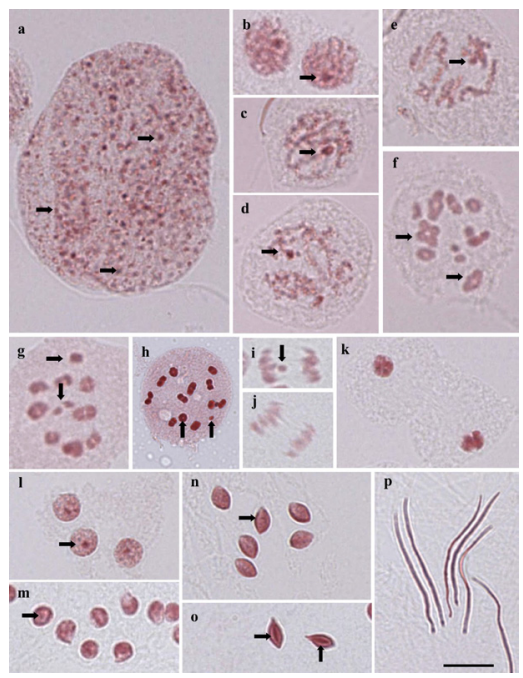

Figure 2. Cells of the seminiferous tubules of adult males of Catorhintha guttula (h) and Hypselonotus fulvus (a, b, c, d, e, f, g) (Coreidae) stained with lacto-acetic orcein. a. Polyploid nucleus with several heteropycnotic bodies (arrows). b-e. Cells in prophase I (leptotene/pachytene) with one heteropycnotic region (arrows). f. Diplotene/ diakinesis showing an interstitial chiasma (arrows). g. Metaphase I shows $2 \mathrm{n}=16 \mathrm{~A}+2 \mathrm{~m}+\mathrm{X} 0$ (arrows). $\mathbf{h}$. Metaphase I shows $2 \mathrm{n}=22 \mathrm{~A}+2 \mathrm{~m}+\mathrm{X} 0$ (arrows). $\mathbf{i}, \mathbf{j}$. Anaphase with or without lagging migration of chromosomes (arrow). k. Telophase. I, m. Round spermatids with round heteropycnotic material (arrows). n, o. Spermatid in elongation with elongated heteropycnotic material (arrows). p. Elongated spermatids. Bar: $10 \mu \mathrm{m}$.

Spermiogenesis begins with round spermatids containing a heteropycnotic region that is rounded as well as long, to form the spermatozoon (Figure 21-p). The heteropycnotic region accompanies spermatid morphology, at least at the beginning of development.

\section{Rhopalidae}

The testes of $N$. sidae are formed by seven testicular lobes enclosed in an orange membrane. 
The polyploid nucleus possessed several heteropycnotic bodies distributed in every nucleus (Figure 3a). The meiotic cells, at the beginning of their development (leptotene/zygotene), possess decondensed chromatin and one to four round heteropycnotic bodies of different sizes (Figure 3b-e). This species has interstitial or terminal chiasmata and the m-chromosomes are separated or near each other (Figure 3f,g). Metaphase I was visualized in polar (Figure 3h,i,k) and lateral views (Figure 3j). In polar view, the autosomes form a ring, with the m-chromosomes in the center forming a pseudobivalent. The sex chromosome was generally located outside the ring of autosomes and appeared heteropycnotic. The chromosome complement of this species is $2 \mathrm{n}=10 \mathrm{~A}+2 \mathrm{~m}+\mathrm{X} 0$. In anaphase I (Figure 31), sister chromatids were observed in each of the recently formed chromosome groups. In anaphase II (Figure 3n), the sex chromosome was observed in only one of the daughter cells. One cell was observed at the end of the meiotic division (telophase, Figure $3 \mathrm{~m}$ ). Spermiogenesis begins with round spermatids, with a round heteropycnotic region located in the periphery of the nucleus (Figure 3o,p). In a more advanced stage of development, the heteropycnotic region migrates to near the nuclear membrane (Figure 3q). When spermatids elongated, a heteropycnotic region was observed in the anterior region of the head, remaining until the end of spermatogenesis (Figure 3r-t).

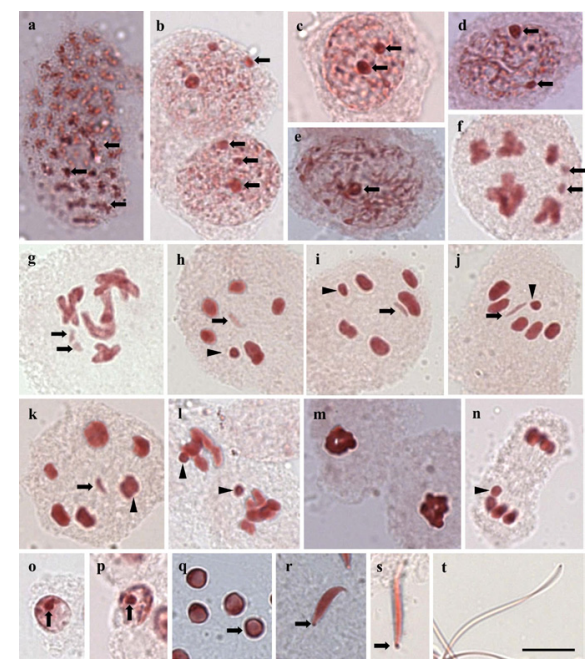

Figure 3. Cells of the seminiferous tubules of adult males of Niesthrea sidae (Rhopalidae) stained with lactoacetic orcein. a. Polyploid nucleus with several heteropycnotic regions (arrows). b-e. Initial prophase I shows a variable number of heteropycnotic regions (arrows). f, g. Diplotene showing the m-chromosomes (arrows) and chromosomes with chiasmata. h, i. Metaphase I, in polar view. j. Metaphase I in lateral view showing 10A $+2 \mathrm{~m}$ $+\mathrm{X} 0$. k. Metaphase I in polar view. In $h, i, j$, and $k$, the arrows indicate the $\mathrm{m}$-chromosomes and the arrowheads indicate the sex chromosome. I. Anaphase I with the heteropycnotic sex chromosomes (arrowheads). m. Telophase. n. Anaphase II, with the sex chromosome (arrowhead). o, p. Round spermatids with heteropycnotic material at the center (arrows). q. Round spermatid with heteropycnotic material distributed along the spermatid (arrow). r-t. Spermatid in elongation with heteropycnotic material in the posterior region of the head (arrows). Bar: $10 \mu \mathrm{m}$.

\section{Nucleolar organizer activity observed in silver-impregnated cells}

The cytogenetic characteristics of spermatogenesis of Hyalymenus sp and $N$. pallescens (Alydidae), C. guttula and H. fulvus (Coreidae) and Niesthrea sidae (Rhopalidae) after silverimpregnation are shown in Table 2. 
H.V. Souza et al.

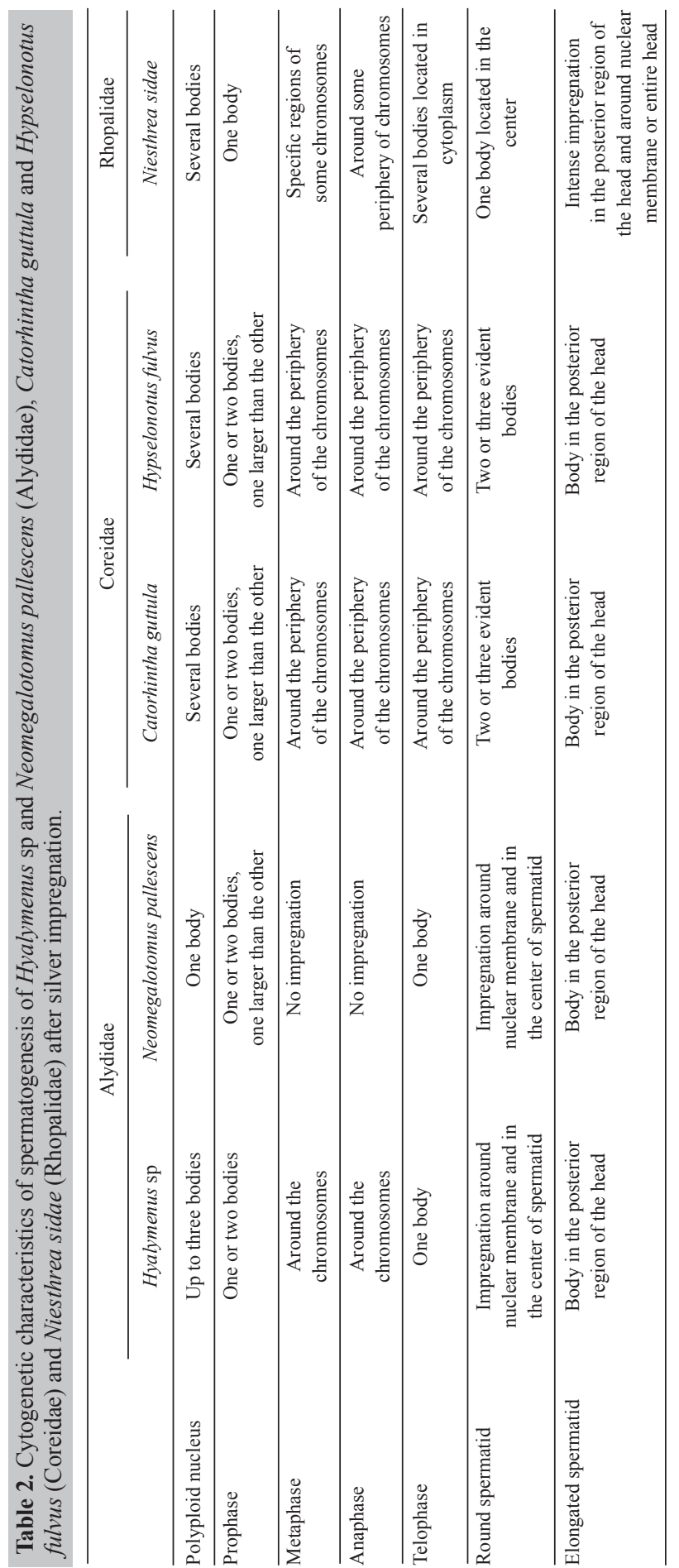




\section{Alydidae}

The polyploid nucleus of $N$. pallescens and Hyalymenus sp impregnated with silver contained one and one to three nucleolar bodies, respectively (Figure 4a-c). In prophase I of meiotic cells (leptotene/zygotene) of both species, one or two nucleolar bodies were visualized, one being larger than the other in N. pallescens (Figure 4d,e). At the end of prophase/ metaphase in Hyalymenus sp, the nucleolar bodies are disorganized, but could be observed as silver-impregnated material present around the periphery of the chromosomes until anaphase (Figure 4f). Conversely, no silver-impregnated material was observed in $N$. pallescens (Figure $4 \mathrm{~g})$. However, in both species, silver-stained bodies were seen in telophase in meiotic cells (Figure 4h); at the beginning of spermiogenesis (while spermatids were round) only a round silver-impregnated body was visualized at the center of the spermatid and around the nuclear membrane. However, this silver-stained material was only observed in the posterior region of the head of the spermatid (Figure 4i-k).

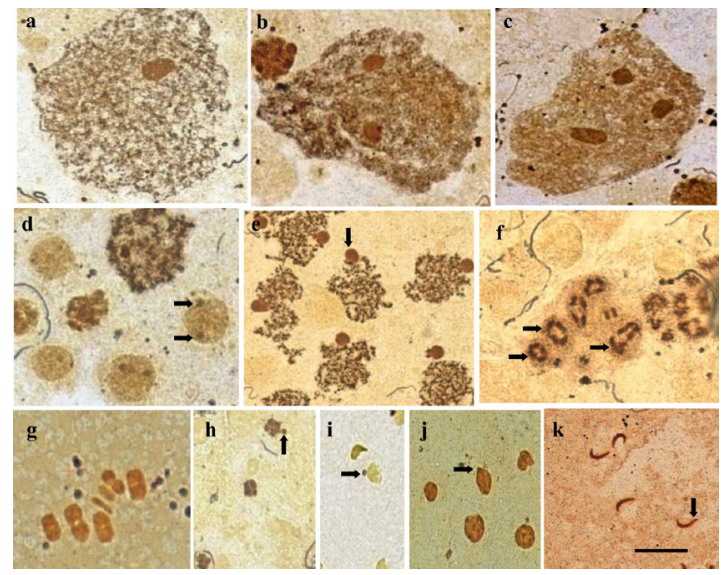

Figure 4. Cells of the seminiferous tubules of adult males of Hyalymenus sp (a, b, c, d, e, f, h, i) and Neomegalotomus pallescens (g, j, k), silver-impregnated. a-c. Polyploid nucleus with up to three nucleoli. d, e. Prophase with one or two nucleoli (arrows). f. Diakinesis with silver impregnation around the chromosomes (arrows). g. Metaphase I. $\mathbf{h}$. Telophase; arrow shows a nucleolar body. i-k. Spermatids; arrows show a nucleolar body. Bar: $10 \mu \mathrm{m}$.

\section{Coreidae}

The polyploid nucleus of C. guttula and H. fulvus possesses several silver-impregnated bodies with very variable morphology and degree of staining (Figure 5a). At the beginning of spermatogenesis, the cells have one or two bodies, one being larger than the another (Figure 5bd), which begin their disorganization at the end of prophase; they could be seen in some specific regions of the chromosomes (Figure 5e,f). During metaphase, anaphase and telophase of both species, the nucleolar material was observed around the periphery of some autosomes (Figure 5g-k).

Round spermatids showed two or three very strongly stained bodies and others less intensely impregnated (Figure 51). During the spermatid elongation process, silver impregnation was restricted to the posterior region of the head, being more evident in C. guttula (Figure 5m-p). 


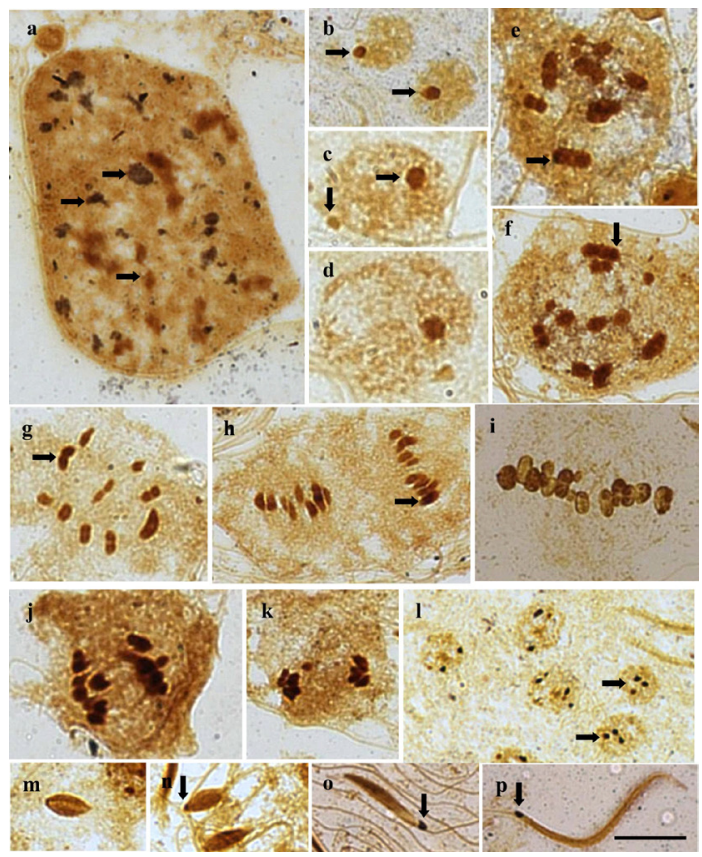

Figure 5. Cells of the seminiferous tubules of adult males of Catorhintha guttula (i,o,p) and Hypselonotus fulvus (a, b, c, d, e, f, g, h, j, k, l, m, n) (Coreidae), silver-impregnated. a. Polyploid nucleus with several silver-impregnated regions (arrows). b-d. Cells in initial prophase with one or two silver-impregnated regions (arrows), which in subsequent phases of development begin their disorganization. e-h. Diakinesis/initial metaphase I with some silver-impregnated chromosome regions (arrows). i. Metaphase I with silver impregnation in the periphery of some chromosomes. j, k. Anaphases with some silver-impregnated chromosomes. l. Round spermatid with several silverimpregnated bodies, three with intense impregnation (arrows). m-p. Elongation spermatids with silver-impregnated posterior region of the head (arrows). Bar: $10 \mu \mathrm{m}$.

\section{Rhopalidae}

We observed several agglomerations of silver-impregnated material with variable morphology and size in the polyploid nucleus of $N$. sidae (Figure 6a). At the beginning of prophase, there was only one silver-impregnated body (Figure 6b). At advanced prophase, this body possessed a more region and another less impregnated region (Figure 6c); it remained disorganized until the end of this phase. During metaphase and anaphase, there were some silver-impregnated chromosomes around the periphery of the chromosomes (Figure 6d-f). The process of the reorganization of nucleolar components was initiated during telophase (Figure $6 \mathrm{~g}$ ). Round spermatids possessed only one rounded body (Figure 6h,i), which began to migrate to the periphery of the spermatid membrane. At the beginning of spermatid elongation, silver-impregnated areas were observed in the posterior region of the head and around the nuclear membrane; subsequently, this silver-stained material was visualized along the entire length of the spermatid (Figure 6j-1). 


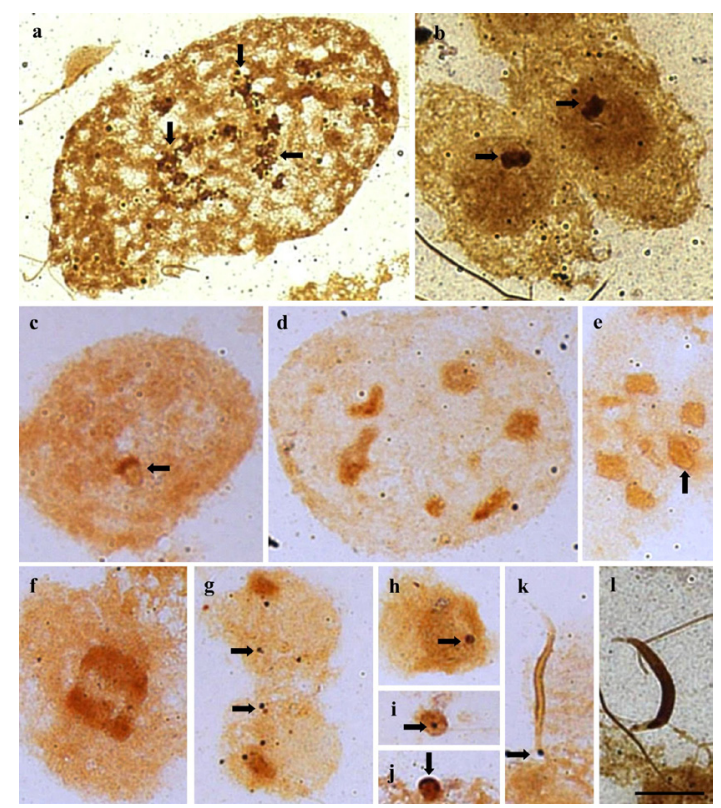

Figure 6. Silver-impregnated cells of the seminiferous tubules of the adult males of Niesthrea sidae (Rhopalidae). a. Polyploid nucleus with several silver-impregnated regions (arrows). b. Initial prophase with a large nucleolar body that is beginning its disorganization (arrows). c. Diplotene with silver impregnation in a region that probably is a nucleolus organizer region (arrow). d. Diplotene/diakinesis evidencing some silver impregnations in the chromosomes. e. Metaphase with silver impregnations of the nucleolus organizer regions (arrow). f. Anaphase with some silver-impregnated chromosomes. g. Telophase with several silver impregnations (arrows). h, i. Round spermatid with a large nucleolar body that migrates to the periphery of the head in $\mathbf{j}$ (arrows). k. Spermatid in elongation with silver-impregnated material along the head of the spermatid with an evident silver-impregnated body in the posterior region (arrow). I. Spermatid at the end of development. Bar: $10 \mu \mathrm{m}$.

\section{DISCUSSION}

Heteroptera testes are formed by variable numbers of testicular lobes and covered by a membrane with different colorations. Antiteuchus tripterus (Pentatomidae, Discocephalinae, Discocephalini) possess testicles covered by a red membrane and constituted of six elongated testicular lobes, among which the sixth is internal to the fifth (Souza et al., 2007c). Mormidea quinqueluteum, Oebalus poecilus and O. ypsilongriseus (Pentatomidae, Pentatominae, Carpocorini) also possess a red membrane covering the testicular lobes, but the number of lobes found was three, four and four, respectively (Souza et al., 2007b). Nine species of Coreidae have seven (Anasa bellator, Athaumastus haematicus, Dallacoris obscura, D. Pictus, Leptoglossus gonagra, L. zonatus, and Sphictyrtus fasciatus) or four testicular lobes (Chariesterus armatus and Zicca annulata), and all of them have a red membrane covering the testicles, except in $Z$. annulata, in which the membrane is yellow and C. armatus, which has a translucent membrane (Souza et al., 2007a).

We found seven testicular lobes in all six species, except $N$. pallescens, which had five. All species were found to have orange membranes surrounding the testes, except for the Alydidae, which had red membranes. The function or origin of this membrane is unknown. 
The reason and relationship for this color and lobe number variation is also unknown. Most of these species were found to have seven testicular lobes, which is apparently ancestral to this group, as proposed by Grozeva and Kusnetsova (1992).

As found in previous reports (Schaefer and Panizzi, 2000, apud Ventura and Panizzi, 2003; Bressa et al., (2001), we confirm the chromosome number of $2 \mathrm{n}=13$ for Alydidae and Rhopalidae. Based on the presence of $\mathrm{m}$-chromosomes, the X0 sex determination chromosome system and the same diploid chromosome number, we conclude that Alydidae and Rhopalidae are closely related, when compared with the Coreidae, which have a modal number of 21 chromosomes, ranging from 13 to 28 (Ueshima, 1979).

It is difficult to establish the ancestral number of chromosomes due to their holokinetic characteristics. Fragmentations and fusions could have occurred (Ueshima and Ashlock, 1980; Jacobs, 2004). Other (molecular) methods will be needed to verify the ancestral chromosome number, especially for the Coreidae.

Our findings on the sex chromosome system, m-chromosomes and karyotype for the Alydidae are similar to previous reports (Manna, 1951; Ueshima, 1979). Only one species in this family, Akbaratus fasciatus, has a karyotype with $2 \mathrm{n}=14, \mathrm{X}_{1} \mathrm{X}_{2} 0$, with two extra pairs of autosomes and two different X chromosomes, but without m-chromosomes (Parshad, 1957, apud Ueshima, 1979). According to Sands (1982), the prevalence of individuals possessing $2 \mathrm{n}=$ 13 chromosomes in most of the genera of Alydidae indicates that this is the ancestral karyotype.

The number and size of the nucleoli are supposedly related to the biosynthetic activity of the cell (Nanya and Bicudo, 1995; Tavares and Azeredo-Oliveira, 1997; Abdo-Banhos et al., 2004). Consequently, differences in the size and number of nucleoli should reflect differences in metabolic activities of the cells.

Bressa et al. (2003), in their study of Dysdercus imitator (Heteroptera; Pyrrhocoridae), suggested that the nucleolus and pre-nucleolar bodies persist in meiosis due to strong demand for rRNA synthesis during spermatogenesis. However, nucleolar proteins continue to be associated with the NORs at metaphase; they are found at the edge of chromosomes during prophase until the beginning of telophase, and are evenly distributed along with RNAs in the cytoplasm during prophase until telophase (Fischer et al., 1991; Wachtler and Stahl, 1993; Schwarzacher and Wachtler, 1993; González-Garcia et al., 1995; Dundr et al., 1997).

We only observed nucleolar proteins around the periphery of the chromosomes in Hyalymenus sp. The physiological meaning for these differences is not clear, as these species are expected to produce similar proteins for spermatogenesis.

\section{ACKNOWLEDGMENTS}

Special thanks go to Dr. Sonia Maria Oliani of the Department of Biology of IBILCE/ UNESP for the cell images and to Dr. Luiz Antônio Alves Costa of the Museu Nacional, Rio Janeiro, RJ, Brazil, for species identification. Research supported by FUNDUNESP, FAPESP, and CNPq.

\section{REFERENCES}

Abdo-Banhos CR, Cordeiro JA, Rosa CS and Bicudo HE (2004). Morphometric study by image analysis of Ag-stained nucleoli in thyroids bearing proliferating lesions. J. Submicrosc. Cytol. Pathol. 36: 37-43. 
Bressa MJ, Papeschi AG and Larramendy ML (2001). Meiotic studies in Largaeus alboornatus Blanchard (Heteroptera, Lygaeidae: Lygaeinae). Caryologia 55: 15-19.

Bressa MJ, Papeschi AG, Fumagalli E, van Doesburg PH, et al. (2003). Cytogenetic and nucleolar meiotic cycle analyses in Dysdercus imitator Blöte, 1931 (Pyrrhocoridae, Heteroptera) from Argentina. Folia Biol. 51: 135-141.

Cattani MV and Papeschi AG (2004). Nucleolus organizing regions and semi-persistent nucleolus during meiosis in Spartocera fusca (Thunberg) (Coreidae, Heteroptera). Hereditas 140: 105-111.

Colombo PC and Bidau CJ (1985). Estudios cromosómicos en Heterópteros argentinos. I. Los cromosomas meióticos de cinco especies de Coreidae. Physis Secc. C 43: 29-40.

Dey SK and Wangdi T (1988). Chromosome number and sex chromosome system in forty-four species of Heteroptera. Chromosome Inf. Serv. 45: 5-8.

Di Castro M, Prantera G, Cipriani L and Rocchi A (1983). Silver staining analysis of nucleolar-organizer activity during spermatogenesis of Asellus aquaticus (Crustacea, Isopoda). Genetica 60: 163-166.

Dundr M, Meier UT, Lewis N, Rekosh D, et al. (1997). A class of nonribosomal nucleolar components is located in chromosome periphery and in nucleolus-derived foci during anaphase and telophase. Chromosoma 105: 407-417.

Fischer D, Weisenberger D and Scheer U (1991). Assigning functions to nucleolar structures. Chromosoma 101: 133-140.

Fossey A and Liebenberg H (1995). Meiosis and nucleolar structures in the stink bug Carlisis wahlbergi Stal (Coreidae: Heteroptera). Cytobios 81: 7-15.

González-Garcia JM, Rufas JS, Antonio C and Suja JA (1995). Nucleolar cycle and localization of NORs in early embryos of Parascaris univalens. Chromosoma 104: 287-297.

González-Garcia JM, Antonio C, Suja JA and Rufas JS (1996). Meiosis in holocentric chromosomes: kinetic activity is randomly restricted to the chromatid ends of sex univalents in Graphosoma italicum (Heteroptera). Chromosome Res. 4: 124-132.

Grozeva S and Kusnetsova V (1992). The Reproductive System of Some Bug Families (Heteroptera, Pentatomorpha). In: Advances in Regulation of Insect Reproduction (Bennettova B, Gelbic I a nd Soldan T, eds.). Institute of Entomology, Czech Academy of Sciences, 97-102.

Howell WM and Black DA (1980). Controlled silver-staining of nucleolus organizer regions with a protective colloidal developer: a 1-step method. Experientia 36: 1014-1015.

Jacobs DH (2004). The evolution of a neo-XY1Y2 sex chromosome system by autosome sex chromosome fusion in Dundocoris nodulicarius Jacobs (Heteroptera: Aradidae: Carventinae). Chromosome Res. 12: 175-191.

Manna GK (1951). A study of the chromosomes during meiosis in 43 species of Indian Heteroptera. Proc. Zool. Soc. 4: 1-116.

Manna GK (1984). Chromosomes in Evolution in Heteroptera. In: Chromosomes in Evolution of Eukaryotic Groups (Sharma AK, ed.). CRC Press, Boca Raton, 189-225.

Motzko D and Ruthmann A (1984). Spindle membranes in mitosis and meiosis of the heteropteran insect Dysdercus intermedius. A study of the interrelationship of spindle architecture and the kinetic organization of chromosomes. Eur. J. Cell Biol. 33: 205-216.

Nanya S and Bicudo HE (1995). Variation of nucleolar area in fat tissue of Drosophila mulleri during development. Cytobios 81: 73-86.

Parshad R (1957). Chromosome number and sex mechanism in 20 species of the Indian Heteroptera. Curr. Sci. 26: 125.

Rufas JS and Giménez-Martín G (1986). Ultrastructure of the kinetochore in Graphosoma italicum (Hemiptera: Heteroptera). Protoplasma 132: 142-148.

Sands VE (1982). Cytological studies of the Coreidae and Alydidae (Hemiptera: Heteroptera). II. Karyological changes exemplified by Malaysian genera. Caryologia 35: 335-345.

Santos J, Sentis C and Fernandez-Piqueras J (1987). Pattern of nucleolar organizer region activity during male meiosis in Callicrania seoanei (Orthoptera) as analyzed by silver staining: evidences for a possible reactivation in the period between the two meiotic divisions. Genome 29: 516-518.

Satapathy SN and Patnaik SC (1989). Chromosome numbers in forty-one species of Indian Heteroptera. Chromosome Inform. Serv. 47: 3-5.

Schaefer CW and Panizzi AR (2000). Heteroptera of Economic Importance. CRC Press, New York.

Schuh TT and Slater JA (1995). The Bugs of the World (Hemiptera: Heteroptera): Classification and Natural History. Cornell University Press, Ithaca.

Schwarzacher HG and Wachtler F (1993). The nucleolus. Anat. Embryol. 188: 515-536.

Souza HV, Arakaki RLM, Dias LN, Murakami AS, et al. (2007a). Cytogenetical aspects of testicular cells in economically important species of Coreidae family (Heteroptera). Cytologia 72: 49-56.

Souza HV, Bicudo HE and Itoyama MM (2007b). Study of chromosomal and nucleolar aspects in testes of Nysius californicus (Heteroptera: Lygaeidae). Genet. Mol. Res. 6: 33-40. 
Souza HV, Bicudo HEMC, Costa LAA and Itoyama MM (2007c). A study of meiosis and spermatogenesis in different testicular lobes of Antiteuchus tripterus (Heteroptera, Pentatomidae). Eur. J. Entomol. 104: 353-362.

Tavares MG and Azeredo-Oliveira MTV (1997). Pattern of nucleolar activity during spermatogenesis in triatomines (Heteroptera, Reduviidae) as analyzed by silver staining. Cytobios 83: 93-103.

Ueshima N (1979). Animal Cytogenetics. Version 3. Insecta 6, Hemiptera: Heteroptera. Gebruder Borntraeger, Berlin, Stuttgart.

Ueshima N and Ashlock PD (1980). Cytotaxonomy of the Lygaeidae (Hemiptera, Heteroptera). Univ. Kansas Sci Bull. 51: 717-801.

Ventura MU and Panizzi AR (2003). Population dynamics, gregarious behavior and oviposition preference of Neomegalotomus parvus (Westwood) (Hemiptera: Heteroptera: Alydidae). Braz. Arch. Biol. Technol. 46: 33-39.

Wachtler F and Stahl E (1993). The nucleolus: a structural and functional interpretation. Micron 24: 473-505.

Wolf KW (1996). Acetylation of $\alpha$-tubulin in male meiotic spindles of Pyrrhocoris apterus, an insect with holokinetic chromosomes. Protoplasma 191: 148-157. 